\title{
Bed radar reflectivity across the north margin of Whillans Ice Stream, West Antarctica, and implications for margin processes
}

\author{
C.F. RAYMOND, ${ }^{1}$ Ginny A. CATANIA, ${ }^{1,2}$ Nadine NERESON,,${ }^{1,3}$ C.J. VAN DER VEEN ${ }^{4}$ \\ ${ }^{1}$ Department of Earth and Space Sciences, Box 351310, University of Washington, Seattle, Washington 98195-1310, USA \\ E-mail: charlie@ess.washington.edu \\ ${ }^{2}$ Institute for Geophysics, University of Texas, Austin, Texas 78759, USA \\ ${ }^{3}$ Philips Medical Systems Ultrasound, 22100 Bothell Everett Highway, Bothell, Washington 98021-8434, USA \\ ${ }^{4}$ Byrd Polar Research Center and Department of Geological Sciences, The Ohio State University, 1090 Carmack Road, \\ Columbus, Ohio 43210-1002, USA
}

\begin{abstract}
Surface-based ice-penetrating radar profiles were made across the active north margin (the Snake) of the upper part of Whillans Ice Stream (formerly Ice Stream B, branch B2), West Antarctica, at three locations. Low frequency (about $2 \mathrm{MHz}$ ) and the ground deployment of the radar allowed penetration through the near-surface zone of fracturing to detect internal layering and bed reflection characteristics on continuous profiles spanning from the slow-moving ice of Engelhardt Ridge well into the chaotic zone of the shear margin. Internal layers were tracked beneath the chaotic zone, where they are warped but remain continuous. The energy returned from internal layers showed no systematic changes associated with the transition from the undisturbed surface of the slow-moving ice into the fractured surface of the shear margin, thus indicating little effect from the surface crevasses on the penetration of the radar signal. Based on this calibration of the near-surface effects and corrections for path length, spreading and attenuation, we examine the spatial variation of bed reflectivity. Low bed reflectivity found under Engelhardt Ridge extends under the chaotic zone of the margin into fast-moving ice. We argue that the fast motion in a band along the margin is mediated by processes other than deformation of thick dilated till that is the source of lubrication allowing fast motion in the interior of the ice stream.
\end{abstract}

\section{INTRODUCTION}

The ice streams of the Siple Coast of the West Antarctic ice sheet (WAIS) are bands of rapidly moving ice that play a crucial role in the discharge of ice to the ocean and the mass balance of the ice sheet (Alley and Whillans, 1991). The margins of these ice streams are sharp, dynamic boundaries separating fast- and slow-moving ice. One of the important enigmas is what determines the location of the margins and how they may shift or not (Raymond and others, 2001). High ice-stream speed and localization of marginal shearing indicates a fairly sharp mechanical transition from good basal lubrication underneath the streaming flow to a locked basal condition in the slow-moving ice to the side, with much of the downslope weight of the ice stream supported by the bed near its edges (Echelmeyer and others, 1994; Scambos and others, 1994; Whillans and Van der Veen, 1997). An important question is: what could maintain a locked condition in these zones of mechanical support in the face of concentration of stress and associated mechanical heating into them (Jacobson and Raymond, 1998; Schoof, 2004)? This question bears on the potential for large discharge increases through ice streams by widening discharge gates and associated speed-up.

Water plays a crucial role in the basal lubrication of these ice streams. Differences in the amount and ionic content of liquid water important in the lubrication process affect electrical properties of the base, and should be detectable using radar (Peters and others, 2005). Indeed, available radar observations indicate generally higher basal reflectivity under ice streams compared to inter-ice-stream ridges (Bentley and others, 1998; Gades and others, 2000; Catania and others, 2003).
Characteristics of the transition in basal reflectivity and its relation to shearing marked by marginal crevasses on the upper surface have barely been explored. Airborne radioecho sounders are typically unable to clearly image internal layers or the bed beneath ice-stream margins because of strong scattering from the crevasses (e.g. Shabtaie and others, 1987). While imaging of the bed can be improved using synthetic aperture radar (SAR) methods (e.g. Peters and others, 2005), quantitative assessment of the bed reflectivity remains difficult. Ground deployment and low frequency allows better penetration through the near-surface fractures. Profiling is relatively easy across buried inactive margins of dormant ice streams, and a number of profiles traversing from an inactive ice stream to an adjacent ridge have revealed spatial features of high to low basal reflectivity transitions (Gades and others, 2000; Catania and others, 2003). A common feature is that transitions in bed reflectivity lie several kilometers inside the outer edges of the marginal crevasse bands. This discordance raises questions about the mechanics of margins. Is the lubrication under a margin of an ice stream different than in its interior? Or are there mechanical processes in the ice that enable concentration of shear straining remote from the edge of lubrication of the ice-stream base? With regard to active icestream mechanics, interpretation of the radar data from these dormant margins is complicated by the dormant condition during observation and over several centuries before, during which drainage and/or freezing of the bed could have occurred. Unfortunately, the active shear margins are not straightforward to traverse, because the crevasses are actively forming and are not buried.

This paper presents the first radar measurements revealing bed reflectivity trends in an active ice-stream margin. It 


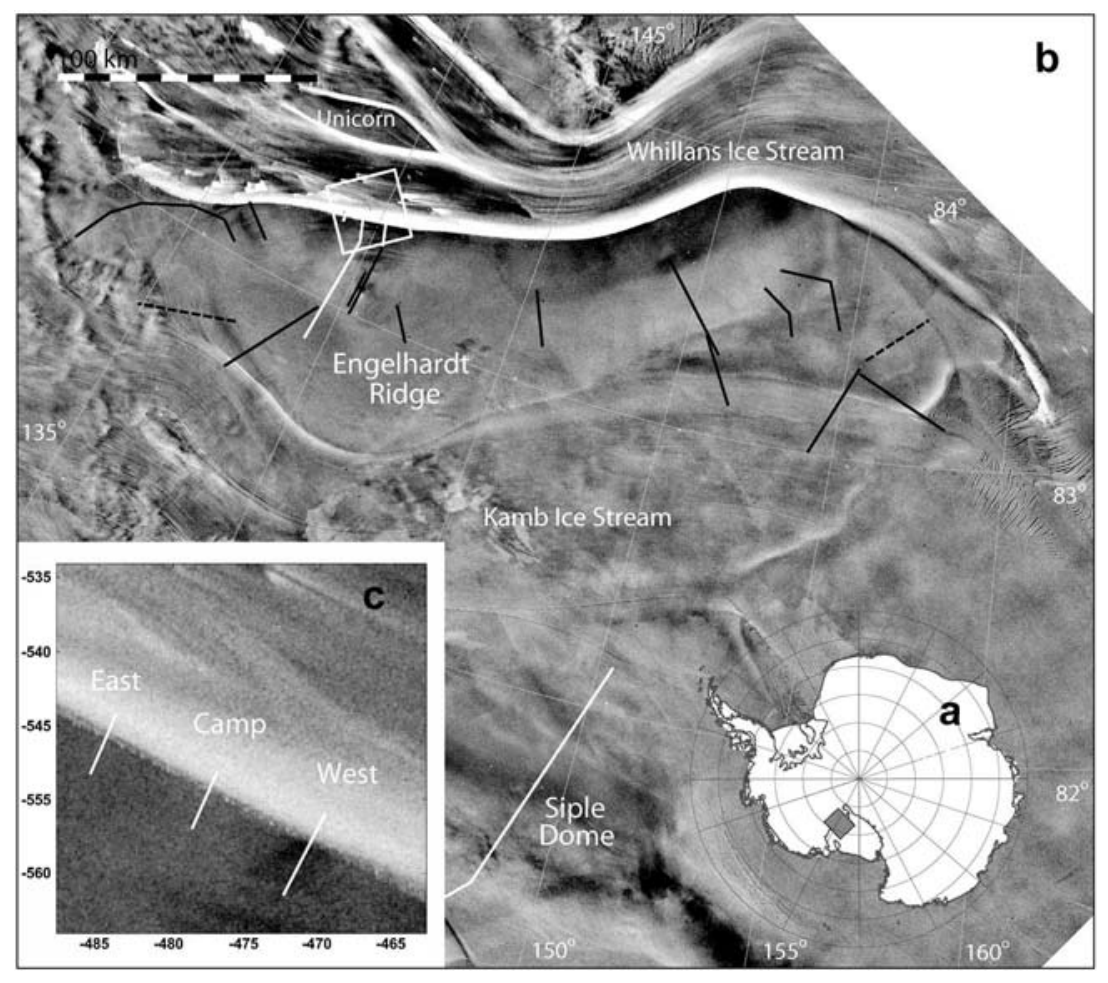

Fig. 1. (a) Location of field area in Antarctica. (b) SAR image of Engelhardt Ridge (ER) and bounding Whillans and Kamb Ice Streams taken from the RADARSAT-1 Antarctic Mapping Project (RAMP) mosaic (Jezek, 1999). Lines indicate the approximate paths of ground-based, lowfrequency radar profiles collected on parts of ER in the last decade (Nereson and Raymond, 2001; Catania and others, 2003 and unpublished information; this paper). White lines show profiles at approximately $2 \mathrm{MHz}$ used in this paper. Black lines show other profiles not used because of higher frequency (nominally $5-7 \mathrm{MHz}$ ) over rough bed areas or instrumental artifacts complicating analysis of power return. Dashed lines are specific profiles from Catania and others (2003) mentioned in the text. White box shows the location of (c). (c) Large-scale image of the WIS margin (Snake) with precise locations (white lines) of three profiles shown in Figure 2. Coordinates are polar stereographic projection in units of $\mathrm{km}$. Horizontal axis is polar stereographic $x$, and vertical is polar stereographic $y$.

examines the north margin (called the Snake) of the upper part of Whillans Ice Stream (WIS) (formerly known as Ice Stream B, branch B2; Fig. 1). The Snake is one of the most spectacular shear margins of the WAIS. The observations begin to place some constraints on the characteristics of the locked to lubricated boundary associated with the present position of this margin.

\section{RADAR PROFILES}

Radar profiles were made across the Snake at three locations spaced about $8 \mathrm{~km}$ along the margin (Fig. 1). Each profile covered a substantial distance on Engelhardt Ridge (ER) and penetrated through the most chaotic zone of the Snake to less disturbed ice toward the interior of the ice stream. This paper is concerned primarily with basal reflection strength from those parts of the profiles lying near and in the margin. The profile Camp extending into ER and across its divide (Fig. 1b) gives information about the large-scale spatial pattern of accumulation on ER and its recent history of flow, as discussed by Nereson and Raymond (2001).

The radar profiling system utilized a high-voltage, impulse transmitter ( $\pm 2000 \mathrm{~V}$ step with $15 \mathrm{~ns}$ rise time) driving a low-frequency dipole antenna with tapered resistive loading to give a transmitted pulse length of about 1.5 period. Returns were received by an identical antenna fed to a digital oscilloscope with internal stacks (typically on the order of $10^{2}-10^{3}$ ) downloaded to a small computer. The basic features of the radar system are described in more detail by Weertman (1993), Morse (1997) and Gades and others (2000). We used antennae with length corresponding to frequency of about $2 \mathrm{MHz}$. The effective center frequency is somewhat higher. The antennae were dragged end-to-end over the firn surface with a center-to-center spacing of about $118 \mathrm{~m}$. On the smooth terrain of ER, the system was drawn by a snowmobile, but it was hauled on foot (with great difficulty) in the crevassed zone of the Snake. Soundings were taken typically every $5 \mathrm{~m}$ in horizontal distance along the profile paths in the Snake as determined by a bicycle wheel. Barometric altimetry was used to determine elevation of the surface at the horizontal position of each record. Both horizontal and vertical positions on the surface were controlled by differential global positioning system spaced at several hundred meters along the profile.

Recorded returns of voltage vs time were de-trended and bandpass filtered (phase-preserving, forward-reverse Butterworth filter with corner frequencies of 1 and $10 \mathrm{MHz}$ ). Depths of returns from beneath the surface were computed from the two-way travel time accounting for velocity of radio waves in the firn and ice, refraction in the firn and antenna geometry (Weertman, 1993) using the vertical variation of density found nearby on ER by Alley and Bentley (1988). To produce images of the geometry of the surface, layers and bed, the voltage return from each horizontal and vertical position sampled in a profile was mapped to grayscale with results shown in Figure 2. 

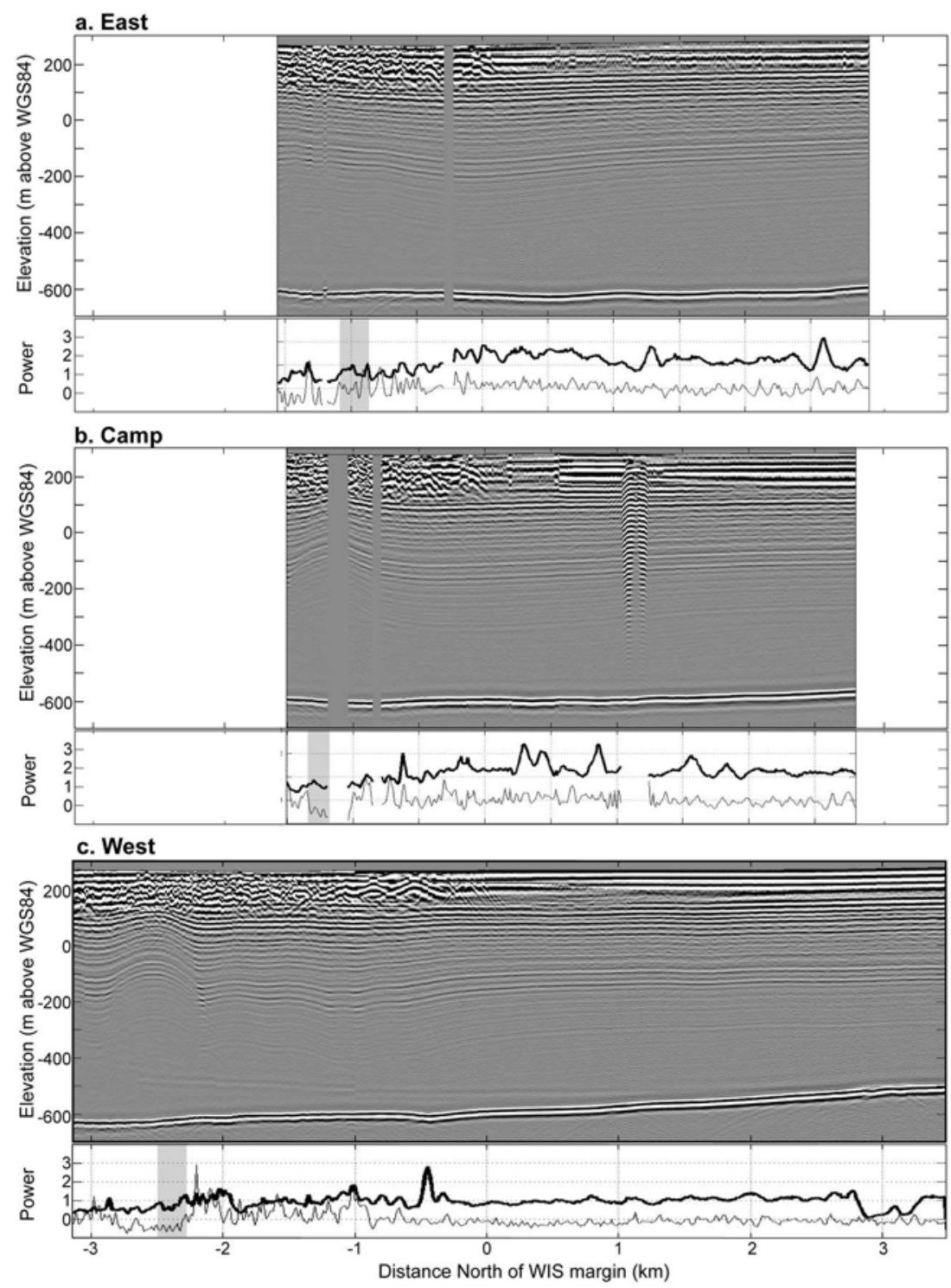

Fig. 2. Radar profiles across the Snake at three locations (Fig. 1b) separated by about $8 \mathrm{~km}$ along the direction of flow of WIS: (a) East profile $\left(83.3042^{\circ} \mathrm{S}, 138.3697^{\circ} \mathrm{W}\right.$ to $\left.83.2667^{\circ} \mathrm{S}, 138.4764^{\circ} \mathrm{W}\right)$; (b) Camp profile $\left(83.318^{\circ} \mathrm{S}, 138.976^{\circ} \mathrm{W}\right.$ to $\left.83.2831^{\circ} \mathrm{S}, 139.0662^{\circ} \mathrm{W}\right)$; and $(\mathrm{c}) \mathrm{West}$ profile $\left(83.345^{\circ} \mathrm{S}, 139.547^{\circ} \mathrm{W}\right.$ to $\left.83.2883^{\circ} \mathrm{S}, 139.6608^{\circ} \mathrm{W}\right)$. Profiles are aligned with 0 distance at the approximate outer edge of the zone of arcuate crevasses. Shaded vertical bar indicates the possible range in location of maximum strain rate. The disturbance at $+1 \mathrm{~km}$ in the Camp profile results from scattering from a radio antenna and other objects in the camp. The panel beneath each profile shows relative power return from the bed $\left(B R P_{R}\right.$; heavy curve) and interior $\left(I R P_{N}\right.$; light curve) as described in the text. Curves of $B R P_{R}$ and $I R P_{N}$ are not smoothed. Curve for $\operatorname{IRP}_{\mathrm{N}}$ is shifted by 1 to separate it from $\mathrm{BRP}_{\mathrm{R}}$.

\section{BED REFLECTIVITY}

\section{Power returned from bed and interior}

The power returned from the bed (abbreviated below as $\mathrm{BRP}$ ) is related to the reflectivity of the bed. However, the system characteristics, near-field interaction with the firn, loss along the propagation path and environmental electromagnetic noise also affect the return power. By using methods similar to those described by Gades and others (2000), power returned from bright internal layers below the zone of crevasses (abbreviated below as IRP) is used to calibrate these additional effects to allow definition of the spatial variation of relative reflectivity from the bed.

The average returned power from within any two-way travel time window $\mathrm{tt}_{1}-\mathrm{tt}_{2}$ is defined as half the mean square voltage $v$ over the interval. In practice, this is evaluated in terms of a sum over the discrete samples $n\left(\mathrm{tt}_{1}\right)$ to $n\left(\mathrm{tt}_{2}\right)$ in the time window

$$
\mathrm{RP}=\frac{1}{2\left[n\left(\mathrm{tt}_{2}\right)-n\left(\mathrm{tt}_{1}\right)+1\right]} \sum_{i=n\left(\mathrm{tt}_{1}\right)}^{n\left(\mathrm{tt}_{2}\right)} v_{i}^{2}
$$

which gives the mean power per sample.

BRP is defined as RP evaluated on the time window of length $T_{\mathrm{b}}$ starting at $T_{\mathrm{b}} / 4$ before the maximum of the wavelet returning from the bed, where $T_{\mathrm{b}}$ is roughly one period of the bed wavelet defined as two times the time difference from the maximum to the first minimum following it. (The typical sampling interval of $10 \mathrm{~ns}$ gives about 20 samples in $T_{\mathrm{b}}$ of about $0.2 \mu \mathrm{s}$.)

IRP is defined on a fixed time window starting at $\mathrm{tt}_{1}=2 \mu \mathrm{s}$ and ending at $\mathrm{tt}_{2}=5.24 \mu \mathrm{s}$. (It includes 324 samples with the typical sampling interval of $10 \mathrm{~ns}$.) This time window for IRP corresponds to a depth range of 


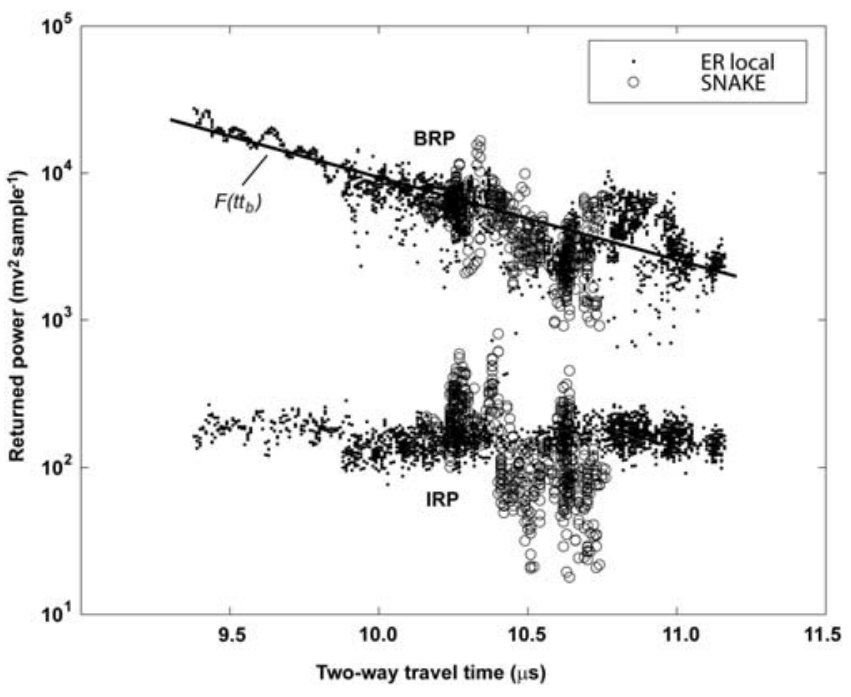

Fig. 3. Power returned from bed BRP and interior IRP vs two-way travel time to the bed, $\mathrm{tt}_{\mathrm{b}}$, for local profiles East, Camp and West (Fig. 1c) including the extension of Camp profile across the divide of ER (Fig. 1b). Different symbols distinguish measurements from ER and those from the Snake. The solid curve represents a function $\mathrm{BRP}=F\left(\mathrm{tt}_{\mathrm{b}}\right)$ fit to data from the ER parts of profiles.

about $202-480 \mathrm{~m}$ and includes only the zone where internal layers are clearly imaged (Fig. 2), thereby excluding effects unrelated to internal scattering at short time from the direct wave along the surface and at long time from noise obscuring dim returns from deep ice. It also excludes the strong bed reflection in all profiles and a variable and sometimes strong disturbance (glitch) associated with the transmitter at about $6 \mu$ s appearing in some profiles.

Some of the power in any time window comes from noise. We use an approximately $1 \mu$ s time window in the last part of the recording interval well below the bed to gauge the noise power level (NP).

Figure 3 shows BRP and IRP displayed according to $t_{b}$ for the local profiles (Fig. 1c) and the extension of the Camp profile across the ER divide (Fig. 1b). For our profiles (on about $0.9 \mathrm{~km}$ thickness) IRP is one to two orders of magnitude smaller than BRP. NP is scattered about $1 \mathrm{mv}^{2}$ per sample. (We do not show NP because it is much less than IRP (more than one order of magnitude), and its inclusion stretches the vertical scale with loss of detail in BRP and IRP.)

BRP is distinctly correlated with $t_{b}$ as a result of path losses from geometrical spreading and attenuation (absorption and scattering). As expected from their definitions, IRP and NP are not correlated with $t_{b}$. There is no clear separation for any of BRP or IRP found under the Snake parts of the profiles (circles in Fig. 3) compared to under ER (points in Fig. 3), although the Snake shows more scatter than ER.

\section{Spatial variation along profiles}

To highlight possible spatial anomalies in bed reflection and compare with internal scattering, it is convenient to de-trend BRP and to normalize IRP.

To approximate the trend in BRP vs $\mathrm{tt}_{\mathrm{b}}$, we define $\mathrm{a}$ smooth empirical function $F\left(t_{b}\right)=0.5 a \exp \left(b t_{b}\right)$ (straight line on the log-linear plot of Fig. 3) by a least-squares fit to BRP vs $t_{b}$. We use the data in Figure 3 excluding those parts of the profiles in the Snake, where we want to investigate the possibility that BRP does not conform to the pattern in the adjacent ER. The resulting least-squares fit gives $a=7.713$ $(5.434,9.993) \times 10^{9} \mathrm{mV}^{2}$ and $b=-1.293(-1.323$, $-1.264) \mu \mathrm{s}^{-1}$, where the range in parentheses shows $95 \%$ confidence bounds. Because of the scatter, the data do not tightly constrain choice of $F\left(\mathrm{tt}_{\mathrm{b}}\right)$ (Fig. 3). In fact, there is no correct $F\left(t_{b}\right)$, given that there could be some degree of spatial variation in ice temperature and chemistry affecting attenuation. However, these are not major problems in our search for a large change in bed reflectivity. The ice thickness (and $t_{b}$ ) varies smoothly without steep gradients along the profiles. Furthermore, the continuity of internal layers suggests no reason to expect discontinuities in the thickness-averaged internal ice temperature or chemistry. Thus, $F\left(t_{b}\right)$ provides a useful model to identify differences in $\mathrm{BRP}$ that are not easily explained solely by $\mathrm{tt}_{\mathrm{b}}$ trends.

We define a relative bed reflection power $B R P_{R}=B R P /$ $F\left(t_{b}\right)$. The detailed spatial variation of $B_{R P}$ for each profile across the Snake is shown below its image in Figure 2. Table 1 gives quantitative statistical information about the spatial variability of $\mathrm{BRP}_{\mathrm{R}}$ for the full profile distances and separately for the parts in ER and in the Snake.

To display the spatial variation of IRP, we define a normalized IRP as $I R P_{N}=I R P / \overline{I R P}$, where $\overline{I R P}$ is the average over the full distance along a profile. $I R P_{N}$ is shown below the corresponding profile image in Figure 2 shifted by 1 to separate it from $\mathrm{BRP}_{\mathrm{R}}$. Table2 gives quantitative statistical information about the spatial variability of $\operatorname{IRP}_{\mathrm{N}}$ for the full distance and separately for the parts in ER and in the Snake.

Both $B R P_{R}$ and $I R P_{N}$ show variation along the profile tracks. They appear to vary independently (Fig. 2). The visual impression is supported by relatively low linear correlation coefficients calculated for the different profiles (East, Camp, West) and segments (ice stream or ridge), which fall in the range $0.1-0.4$. Examination of each profile individually in the order East, Camp, West shows that correlation is slightly higher in the ice-stream segments $(0.44,0.29,0.37)$ compared to the ridge segments $(0.26,0.28,0.10)$. The lack of negative correlation indicates that backscattering from

Table 1. Statistics of relative bed return power variations

\begin{tabular}{|c|c|c|c|c|c|c|c|c|c|c|c|c|}
\hline \multirow[b]{2}{*}{ Name } & \multicolumn{4}{|c|}{ Full profile } & \multicolumn{4}{|c|}{ Ice-stream part } & \multicolumn{4}{|c|}{ Ridge part } \\
\hline & Mean & $\mathrm{rms}$ & Max. & Min. & Mean & $\mathrm{rms}$ & Max. & Min. & Mean & $\mathrm{rms}$ & Max. & Min. \\
\hline East & 1.09 & 0.38 & 2.16 & 0.21 & 0.83 & 0.42 & 1.83 & 0.21 & 1.24 & 0.26 & 2.16 & 0.72 \\
\hline Camp & 1.19 & 0.36 & 2.40 & 0.34 & 0.96 & 0.36 & 2.02 & 0.34 & 1.31 & 0.24 & 2.40 & 0.91 \\
\hline West & 0.93 & 0.33 & 2.83 & 0.00 & 0.90 & 0.37 & 2.83 & 0.29 & 0.96 & 0.29 & 1.53 & 0.00 \\
\hline
\end{tabular}


layers is not a prevailing factor in attenuating BPR as would also be expected from the low IRP. The small positive correlation suggests some variability in the transmission of radar power to and through the near surface. The somewhat more positive correlation together with a very slightly lower mean for both $B R P_{R}$ and IRP and larger spread for IRP $P_{N}$ in the ice stream compared to the ridge (Tables 1 and 2) suggests a detectable but small extra loss by scattering from nearsurface crevasses.

Examination of the more detailed spatial variation of both $B R P_{R}$ and $I R P_{N}$ shown in Figure 2 does not reveal any distinct shift in either BRP or IRP across the edge of the ice stream or any boundary inward that would suggest large jumps in radar penetration through the upper surface, column ice properties or bed reflectivity. We have also examined the reflection power from individual internal layers, which like IRP do not show any spatial trends associated with the margin position. $B R P_{R}$ is slightly larger than is typical just inside the margin on the West profile and just outside the margin on the Camp profile. However, anomalies of similar or larger size are found for both $B R P_{R}$ and $I R P_{N}$ away from the margin, thus calling into question any significance to the near-margin patterns. In general, the largest anomalies in $\mathrm{BRP}_{\mathrm{R}}$ appear to be associated with locations of high bed curvature that could cause focusing or defocusing or locations of roughness elements as indicated by diffraction hyperbola (e.g. West profile at $-0.5 \mathrm{~km}$ and $3.0 \mathrm{~km}$ ).

The conclusion is that the radar sees no significant difference in bed reflection properties in the Snake compared to ER. The difference in average basal reflectivity between the sampled parts of the ridge and of the Snake is less than about $\pm 20 \%$ (Table1). This is much smaller than the reflectivity contrast up to about a factor of 6 from ridge to ice stream known in some places as discussed below.

\section{Magnitude along profiles}

The procedure that we have followed reveals only (lack of) relative changes in reflectivity but not absolute values, which would also be useful to know. To obtain some constraints for this part of ER and the adjacent Snake, we examine already published data from other WAIS locations together with ours. Interpretation is not straightforward, since the available data were not all gathered with identical configuration or calibrated radar systems. We follow related paths ultimately based on the constraint that 1 is an upper reflectivity limit.

First, we compare our local area of ER to Siple Dome (SDM). Gades and others (2000) deduced a relatively low bed power reflectivity (less than about 0.14) under SDM, because it was substantially lower there (by a factor of $1 / 7$ ) than in the adjacent 'Siple Ice Stream'. Radar at SDM and ER both used similar low frequency but different antenna

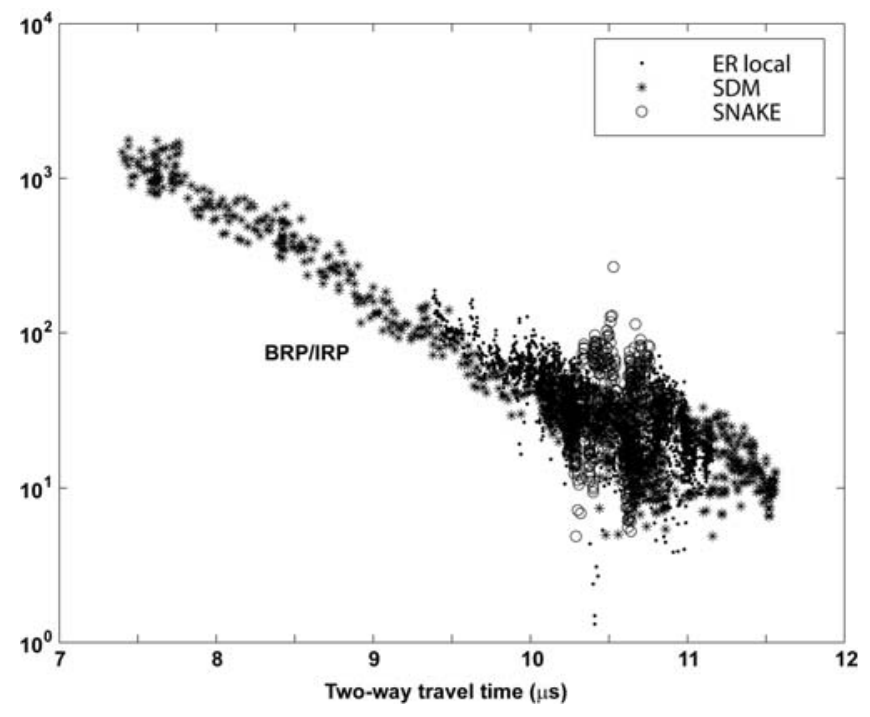

Fig. 4. Power returned from the bed BRP scaled to power from the interior IRP vs the corresponding two-way travel time to the bed, $t_{b}$, for profiles collected with approximately $2 \mathrm{MHz}$ impulse radar. Different symbols indicate source of data. ER local and Snake are from BRP and IRP in Figure 3. SDM are from Siple Dome (Fig. 1b) using data from Jacobel and others (1996) and Gades and others (2000).

loading, transmitter and receiver. As above, we use IRP to inter-calibrate the systems by examining BRP/IRP in Figure 4. Both BRP and IRP found on Siple Dome are about one order of magnitude smaller than the corresponding quantity in our area of ER (Fig. 3), but BRP/IRP is nearly the same. The parallel behavior of BRP and IRP is most simply explained by different system characteristics (and possibly different near-surface coupling) interacting with nearly the same internal scattering and bed reflection under SDM and our local area of ER.

Second, we compare other areas of ER where measured profiles span both ridge and ice-stream environments. Nominally $5 \mathrm{MHz}$ profiles pass from the lower (west) part of ER into a stagnated part of WIS and from the upper (east) part of ER into a now dormant connection from WIS to Kamb Ice Stream (Fig. 1b). Both show distinctly higher bed power reflectivity (by up to an order of magnitude) in parts of the former streaming areas compared to ER (Catania and others, 2003, figs 3 and 4), thus capping the power reflectivity beneath these areas of ER at low values (less than roughly 0.1 ). Airborne $50 \mathrm{MHz}$ radar analyzed by Bentley and others (1998) indicates a similar upper limit for power reflectivity beneath wide areas of the western part of ER, as shown by substantially lower values than in the interiors of both Kamb Ice Stream (larger by about one order

Table 2. Statistics of normalized internal return power variations

\begin{tabular}{|c|c|c|c|c|c|c|c|c|c|c|c|c|}
\hline \multirow[b]{2}{*}{ Name } & \multicolumn{4}{|c|}{ Full profile } & \multicolumn{4}{|c|}{ Ice-stream part } & \multicolumn{4}{|c|}{ Ridge part } \\
\hline & Mean & $\mathrm{rms}$ & Max. & Min. & Mean & $\mathrm{rms}$ & Max. & Min. & Mean & $\mathrm{rms}$ & Max. & Min. \\
\hline East & 1.00 & 0.28 & 2.18 & 0.23 & 1.00 & 0.40 & 2.18 & 0.23 & 1.00 & 0.18 & 1.51 & 0.48 \\
\hline Camp & 1.00 & 0.27 & 2.04 & 0.12 & 1.02 & 0.38 & 2.04 & 0.12 & 0.98 & 0.20 & 1.81 & 0.57 \\
\hline West & 1.00 & 0.40 & 3.90 & 0.00 & 1.14 & 0.51 & 3.90 & 0.23 & 0.87 & 0.15 & 1.38 & 0.00 \\
\hline
\end{tabular}


of magnitude) and WIS (larger by about a factor of 3). We do not attempt to directly compare these data from other ER locations with our local ER data, because of differences in frequency and related antennae configuration that could affect BRP and IRP differently. Nevertheless, these data from other ER locations support low power reflectivity $(<0.1)$ under broad areas of ER.

Collectively, the published data indicate bed power reflectivity beneath our local ER area that is substantially lower than in some ice-stream areas and does not exceed $0.1-0.2$. Our local results also show that low reflectivity extends beneath the Snake.

\section{CONTEXT FOR INTERPRETATION}

\section{Margin mechanics}

The presence of a narrow, chaotic shear zone at the Snake indicates that it is underlain by a large, sharp transition in the lubrication of the bed going from locked under ER to well lubricated under WIS. Flow models provide some constraints on the spatial relationship between the shear zone on the upper surface and the lubrication transition at the bed causing it.

With homogeneous mechanical properties of the ice, the maximum shear strain rate on the surface is predicted to lie almost directly over the lubrication jump on the bed, when it is very sharp (Raymond, 1996). If the transition in lubrication is spread out (e.g. Schoof, 2004), the location of maximum shear strain rate on the surface lies toward the ice-stream center from the outer edge of enhanced basal slip, which is driven by a combination of elevated basal shear stress and heightened lubrication. Modeling shows that some of the fast motion in the outer margin results from high internal deformation near the bed induced by high stress transmitted laterally in the relatively cold, stiff upper part of the ice column (e.g. Whillans and Van der Veen, 2001). Accounting for a temperature effect on ice deformation predicts an inward shift of the strain-rate maximum toward the icestream center (Jacobson and Raymond, 1998), but only by a small amount (a few hundred meters) probably because the effective viscosity stratification caused by temperature variation introduces dominantly vertical gradients. Large outward shifts of the peak in surface strain rate from the outer edge of basal lubrication would require a basal zone of very soft ice connecting to a similarly soft vertical band guiding high strain rate upward to the surface. Although we contrive this rather complex structure here, it is not expected. Correspondingly, it has not been explored in models. It is not clear what size of displacement of strain-rate peak would be possible within the constraint of no more than one order of magnitude softening associated with strong singlemaximum $c$-axis fabric (Budd and Jacka, 1989). Furthermore, maintaining this structure in the face of inflow of ice from the ridge is problematic.

The balance of theoretical understanding indicates that the bed inward from the location of maximum shear strain rate on the surface should be well lubricated. The location of maximum strain rate is known for each profile from measurements on displacement of poles set along the profile (Van der Veen and others, unpublished information). The location is shown in Figure 2 (shading).

On this basis, the radar profiles would be expected to have extended into the ice stream sufficiently far to be sampling well-lubricated parts of the bed under the Snake.
Thus, our observation above means that the bed can pass from lubricated to locked without a significant change in bed reflectivity. In the remainder of this paper, our central question is what implication that has for lubrication conditions under the Snake.

\section{Basal conditions}

Subglacial till plays a central role in the basal lubrication of the Siple Coast ice streams (Kamb, 2001). Seismic methods (Blankenship and others, 1987) and extensive basal sampling through boreholes (Engelhardt and others, 1990; Kamb, 2001) show that a multi-meter thick layer of dilated, watersaturated basal till lies beneath the central zone of WIS close to the area of the Snake examined here. Electrical conductivity of pore water was found to be $2.5 \times 10^{-2} \mathrm{~S} \mathrm{~m}^{-1}$ by direct sampling in boreholes (Engelhardt and others, 1990).

Information about bed conditions beneath inter-icestream ridges is still very limited. Anandakrishnan and Winberry (2004) have identified $300 \mathrm{~m}$ of sediments beneath Siple Dome, based on seismic measurements. However, basal till with morphology like that found under ice streams was not found in boreholes penetrating to the bed under the summit of Siple Dome (Engelhardt, 2003). Basal till has been found in boreholes on the Unicorn (Fig. 1) outside of the shear margin known as the Dragon on the other (south) side of WIS (Kamb, 2001). Since streaming is known to have occurred in this area when the Dragon was further to the south in the past, it is actually stagnant ice stream. Unfortunately, there has not been any basal sampling in ER to provide direct information to guide interpretation of our radar results.

With regard to the thermal regime, heat-flow modeling together with borehole measurements indicate basal temperatures close to the melting point are pervasive in both ice streams and inter-ice-stream areas (Hulbe and Payne, 2001; Joughin and others, 2004). The abundant water beneath WIS and other ice streams shows that basal temperature is at the melting point. The available data give basal temperature within $1-2 \mathrm{~K}$ of the melting point beneath ridges (Kamb, 2001; Engelhardt, 2003). Specifically with regard to this area of ER, downward extrapolation of temperature measurements over part of the ice thickness using thermal modeling indicates basal temperature close to the melting point (Alley and Bentley, 1988).

\section{IMPLICATIONS FOR MARGIN PROCESSES}

One expects relatively high $(>0.2)$ power reflectivity from thick till dilated with conductive pore water (Peters and others, 2005, table I) as found beneath the central parts of WIS (Engelhardt and others, 1990). The bed reflectivity of this area of WIS has not been measured to directly confirm this expectation. However, the high bed reflectivity found under other ice-stream locations including parts of WIS further downstream (Bentley and others, 1998; Gades and others, 2000; Catania and others, 2003) is probably associated with wet basal till. On this basis, we argue that the thick, dilated basal till known to be present in the center of WIS does not extend under the Snake (or exist under this local area of ER). A corollary is that the lubrication under the Snake occurs without thick, wet, dilated till.

Although we exclude any bed morphology with high reflectivity under the Snake, it is problematic to say what is there. One potential model to focus discussion is a smooth 
bed surface of low reflectivity lubricated by small amounts of water. If the lubricating water were thin (several $\mathrm{mm}$ or less) with electrical conductivity found under WIS, it would not be detected in comparison to a dry bed by the radar (Gades and others, 2000). With cleaner water, thicker amounts of water could go undetected. Most probably the water would be fragmented into linked gaps or dispersed in pores of a thin, dilated till slurry.

An obvious, and probably unanswerable, question in this characterization is the composition and structure of the relatively non-reflective substrate. Some combination of low porosity and clean pore water is probably an essential feature. Till or other sediment that has been consolidated over considerable thickness, for example as a result of desiccation through removal of pore water to a freezing interface (Tulaczyk, 1997) sometime in the past, is one possibility.

Partially frozen pore water in the substrate is another consideration. However, it is less compelling. Partially frozen till within a few degrees of bulk pressure-melting point can retain fairly high basal reflectivity (Jiracek, 1967; Hoekstra and Delaney, 1974) because of residual pore water with high electrical conductivity maintained by surface interactions and concentrated impurities. In any case, partially frozen till beneath a wet lubricated bed surface as under the Snake would imply transient thermal conditions, with the wet bed condition being recently established by water injection along the bed or dynamic heating associated with recent outward migration.

\section{DISCUSSION}

The spatial pattern of reflectivity associated with the Snake is consistent with the findings in the margins of dormant ice streams where jumps in bed reflectivity can be several kilometers $(4-10 \mathrm{~km})$ inside the outer edge of buried crevasses (Catania and others, 2003). Evidently this feature of stagnant margins may not be just a consequence of basal drainage or freezing after shutdown, but may have been present even during active motion. Correspondingly, it could be common for active margins. Consideration of till continuity suggests a partial explanation. Since flow of ice from an adjacent ridge toward an ice stream is dominated by internal deformation without significant basal motion, the ice flow across the margin is not accompanied by advection of basal till. Basal motion in the margin itself would tend to sweep deforming till away into the ice-stream flow. Any dilated till layer would have to be built up by activation of local substrate material and would likely remain thin and not reflective.

While our data from the Snake provide a snapshot in 1998/99 and our discussion concerns bed conditions at that time, the recent history of this part of the Snake may have involved recent rapid outward migration. Stearns and others (2005) compared aerial photography in 1987 with satellitebased SAR in 1997 and found evidence for approximately a $2 \mathrm{~km}$ outward (northward) jump of the Snake upstream from our measurements. Such a rapid jump of the Snake into the slope of ER would have implications for surface topography and internal layer geometry that we do not take up here. Accepting that such a jump may have happened, it is enticing to interpret the low bed reflectivity under the Snake to be a consequence of the recent initiation of lubrication with small amounts of clean meltwater and newly activated substrate that are not yet detectable. Correspondingly, the radar provides no evidence for any substantial difference in bed morphology going from the present Snake position into ER. Therefore, the possibility of (further) outward migration and that such migration could happen without dilation of a thick packet of till cannot be discounted. With regard to past margin positions, the lack of major disturbance in the internal layers outside the present margin indicates that it has not been further out in the recent past.

The present Dragon shear margin just across from these measurements appears to present a different situation. The Dragon has been migrating outward at slow speed on the order $10^{1} \mathrm{~m} \mathrm{a}^{-1}$ (Harrison and others, 1998; Echelmeyer and Harrison, 1999) toward a former margin identified by a lineation on the surface (called the Fishhook) from which it earlier migrated inward at higher speed of order $10^{2} \mathrm{~m} \mathrm{a}^{-1}$ for about 200 years (Clarke and others, 2000). As mentioned above, borehole measurements determine that basal till is present under this transient ice-stream area. It is plausible that the ongoing expansion is associated with reactivation of that basal till. Similar circumstances are likely to hold for other now or earlier active margins that are known to be inside former areas of active streaming motion, such as the most recent north margin of Kamb Ice Stream (Jacobel and others, 2000) and the present Snake further to the west close to where it reaches the Ross Ice Shelf (Catania and others, 2003).

\section{CONCLUSION}

Ground deployment of a low-frequency radar system allows imaging of the subsurface beneath the chaotic zone of icestream margins. Internal layers of ER extend without disruption beneath the active north margin of WIS. Radar returns from internal layers enable calibration of propagation losses through the fractured near surface and evaluation of spatial changes in relative reflectivity of the bed. Large contrasts in basal reflectivity between the adjacent ER and the active margin were not detected. An expected jump in reflectivity from low values beneath the ridge to high values in the central parts of WIS associated with wet, dilated till must lie inboard of the Snake. Lubrication under the Snake must have different character than in the central parts of the ice stream relying on relatively small amounts of water with at most sub-meter thickness of dilated till.

\section{ACKNOWLEDGEMENTS}

This research was supported by US National Science Foundation grant Nos. OPP-9725882 and OPP-9909469. The expertise of $\mathrm{M}$. Conway contributed immeasurably to our field operations within the fractured terrain of the Snake. Collaboration with a field team concurrently measuring strain distribution in the Snake, led by the late I. Whillans, with support from OPP-9615127, provided much collegial encouragement and essential back-up for safe work of our three-member field team. C.J.v.d.V. acknowledges support from NASA through NAG5-11383. L. Stearns provided information about the location of maximum strain rate in the margin that enabled our discussion of the bed reflectivity pattern. Comments from two reviewers (R. Jacobel and anonymous) led to substantial improvements in the manuscript. 


\section{REFERENCES}

Alley, R.B. and C.R. Bentley. 1988. Ice-core analysis on the Siple Coast of West Antarctica. Ann. Glaciol., 11, 1-7.

Alley, R.B. and I.M. Whillans. 1991. Changes in the West Antarctic ice sheet. Science, 254(5034), 959-963.

Anandakrishnan, S. and J.P. Winberry. 2004. Antarctic subglacial sedimentary layer thickness from receiver function analysis. Global Planet. Change, 42(1-4), 167-176.

Bentley, C.R., N. Lord and C. Liu. 1998. Radar reflections reveal a wet bed beneath stagnant Ice Stream $C$ and a frozen bed beneath ridge BC, West Antarctica. J. Glaciol., 44(146), 149-156.

Blankenship, D.D., C.R. Bentley, S.T. Rooney and R.B. Alley. 1987. Till beneath Ice Stream B. 1. Properties derived from seismic travel times. J. Geophys. Res., 92(B9), 8903-8911.

Budd, W.F. and T.H. Jacka. 1989. A review of ice rheology for ice sheet modelling. Cold Reg. Sci. Technol., 16(2), 107-144.

Catania, G.A., H.B. Conway, A.M. Gades, C.F. Raymond and H. Engelhardt. 2003. Bed reflectivity beneath inactive ice streams in West Antarctica. Ann. Glaciol., 36, 287-291.

Clarke, T.S., C. Liu, N.E. Lord and C.R. Bentley. 2000. Evidence for a recently abandoned shear margin adjacent to Ice Stream B2, Antarctica, from ice-penetrating radar measurements. J. Geophys. Res., 105(B6), 13,409-13,422.

Echelmeyer, K.A. and W.D. Harrison. 1999. Ongoing margin migration of Ice Stream B, Antarctica. J. Glaciol., 45(150), 361-369.

Echelmeyer, K.A., W.D. Harrison, C. Larsen and J.E. Mitchell. 1994. The role of the margins in the dynamics of an active ice stream. J. Glaciol., 40(136), 527-538.

Engelhardt, H. 2003. Ice temperature and high geothermal flux at Siple Dome, West Antarctica, from borehole measurements. J. Glaciol., 50(169), 251-256.

Engelhardt, H., N. Humphrey, B. Kamb and M. Fahnestock. 1990. Physical conditions at the base of a fast moving Antarctic ice stream. Science, 248(4951), 57-59.

Gades, A.M., C.F. Raymond, H. Conway and R.W. Jacobel. 2000. Bed properties of Siple Dome and adjacent ice streams, West Antarctica, inferred from radio-echo sounding measurements. J. Glaciol., 46(152), 88-94.

Harrison, W.D., K.A. Echelmeyer and C.F. Larsen. 1998. Measurement of temperature in a margin of Ice Stream B, Antarctica: implications for margin migration and lateral drag. J. Glaciol., 44(148), 615-624.

Hoekstra, P. and A.J. Delaney. 1974. Dielectric properties of soils at UHF and microwave frequencies. J. Geophys. Res., 79(11), 1699-1708.

Hulbe, C.L. and A.J. Payne. 2001. The contribution of numerical modelling to our understanding of the West Antarctic ice sheet. In Alley, R.B. and R.A. Bindschadler, eds. The West Antarctic ice sheet: behavior and environment. Washington, DC, American Geophysical Union, 201-219. (Antarctic Research Series 77.)

Jacobel, R.W., T.A. Scambos, C.F. Raymond and A.M. Gades. 1996. Changes in the configuration of ice stream flow from the West Antarctic ice sheet. J. Geophys. Res., 101(B3), 5499-5504.

Jacobel, R.W., T.A. Scambos, N.A. Nereson and C.F. Raymond. 2000. Changes in the margin of Ice Stream C, Antarctica. J. Glaciol., 46(152), 102-110.
Jacobson, H.P. and C.F. Raymond. 1998. Thermal effects on the location of ice stream margins. J. Geophys. Res., 103(B6), $12,111-12,122$.

Jezek, K.C. 1999. Glaciological properties of the Antarctic ice sheet from RADARSAT-1 synthetic aperture radar imagery. Ann. Glaciol., 29, 286-290.

Jiracek, G.R. 1967. Radio sounding of Antarctic ice. Univ. Wisc. Geophys. Polar Res. Cent. Res. Rep. Ser. 67-1.

Joughin, I., S. Tulaczyk, D. MacAyeal and H. Engelhardt. 2004. Melting and freezing beneath the Ross ice streams, Antarctica. J. Glaciol., 50(168), 96-108.

Kamb, B. 2001. Basal zone of the West Antarctic ice streams and its role in lubrication of their rapid motion. In Alley, R.B. and R.A. Bindschadler, eds. The West Antarctic ice sheet: behavior and environment. Washington, DC, American Geophysical Union, 157-199. (Antarctic Research Series 77.)

Morse, D.L. 1997. Glacier geophysics at Taylor Dome, Antarctica. (PhD thesis, University of Washington.)

Nereson, N.A. and C.F. Raymond. 2001. The elevation history of ice streams and the spatial accumulation pattern along the Siple Coast of West Antarctica inferred from ground-based radar data from three inter-ice-stream ridges. J. Glaciol., 47(157), 303-313.

Peters, M.E., D.D. Blankenship and D.L. Morse. 2005. Analysis techniques for coherent airborne radar sounding: application to West Antarctic ice streams. J. Geophys. Res., 110(B6), B06303. (10.1029/2004JB003222.)

Raymond, C. 1996. Shear margins in glaciers and ice sheets. J. Glaciol., 42(140), 90-102.

Raymond, C.F., K.A. Echelmeyer, I.M. Whillans and C.S.M. Doake. 2001. Ice stream shear margins. In Alley, R.B. and R.A. Bindschadler, eds. The West Antarctic ice sheet: behavior and environment. Washington, DC, American Geophysical Union, 137-155. (Antarctic Research Series 77.)

Scambos, T.A., K.A. Echelmeyer, M.A. Fahnestock and R.A. Bindschadler. 1994. Development of enhanced ice flow at the southern margin of Ice Stream D, Antarctica. Ann. Glaciol., 20, $313-318$.

Schoof, C. 2004. On the mechanics of ice-stream shear margins. J. Glaciol., 50(169), 208-218.

Shabtaie, S., I.M. Whillans and C.R. Bentley. 1987. The morphology of Ice Streams A, B, and C, West Antarctica, and their environs. J. Geophys. Res., 92(B9), 8865-8883.

Stearns, L.A., K.C. Jezek and C.J. van der Veen. 2005. Decadalscale variations in ice flow along Whillans Ice Stream and its tributaries, West Antarctica. J. Glaciol., 51(172), 147-157.

Tulaczyk, S. 1997. Freeze-on-driven consolidation of till; a general mechanism for stopping an ice stream? [Abstract H31B-02.] Eos, 78(46), Fall Meet. Suppl., F252.

Weertman, B.R. 1993. Interpretation of ice sheet stratigraphy: a radio-echo sounding study of the Dyer Plateau, Antarctica. (PhD thesis, University of Washington.)

Whillans, I.M. and C.J. van der Veen. 1997. The role of lateral drag in the dynamics of Ice Stream B, Antarctica. J. Glaciol., 43(144), 231-237.

Whillans, I.M. and C.J. van der Veen. 2001. Transmission of stress between an ice stream and interstream ridge. J. Glaciol., 47(158), 433-440. 